\title{
OS DESAFIOS DE PRODUÇÃO DE TELEJORNAIS UNIVERSITÁRIOS INCLUSIVOS: OS CASOS DO PAMPA NEWS E DO EM PAUTA TV
}

\section{THE CHALLENGES OF PRODUCTION OF INCLUSIVE UNIVERSITY TELEJORNS: THE CASES OF PAMPA NEWS AND EM PAUTA TV}

\author{
Michele Negrini*, Roberta Ross**
}

\begin{abstract}
Resumo
Os telejornais universitários são espaços que dão suporte ao ensino e que possibilitam o desenvolvimento de atividades práticas para os estudantes de comunicação. O telejornalismo vem passando por reconfigurações, que buscam atingir uma audiência diversificada e isso não é diferente com os telejornais produzidos no meio acadêmico. Além disso, há a preocupação de considerar as questões inclusivas, que precisam ser fomentadas nas universidades também. Diante disso, a proposta deste artigo é fazer uma reflexão sobre os telejornais universitários, levando em consideração as práticas inclusivas desenvolvidas neste espaço. Tomamos como objeto de discussão e análise o Pampa News, desenvolvido na Unipampa, e o Em Pauta TV, da UFPEL, evidenciando os movimentos e adaptações feitos nos dois programas com vistas à inclusão.
\end{abstract}

Palavras-chave: Telejornalismo universitário. Produção inclusiva. Pampa News. Em Pauta TV.

\begin{abstract}
The university news programs are spaces that support the teaching and that enable the development of practical activities for communication students. Telejournalism has been undergoing reconfigurations, which seek to reach a diverse audience and this is no different with the television news produced in the academic world. In addition, there is concern to consider inclusive issues, which need to be fostered in universities as well. Therefore, the proposal of this article is to reflect on the university news programs, taking into account the inclusive practices developed in this space. We took as object of discussion and analysis the Pampa News, developed at Unipampa, and Em Pauta TV, from UFPEL, showing the movements and adaptations made in the two programs with a view to inclusion.
\end{abstract}

Keywords: University television journalism. Inclusive production. Pampa News. Em Pauta TV.

\footnotetext{
* Jornalista. Doutora em Comunicação pela PUC-RS. Tem pós-doutorado pela Universidade Federal da Bahia (UFBA), no programa de pós-graduação em Comunicação e Cultura Contemporâneas. Professora da Universidade Federal de Pelotas (UFPel). Integrante do núcleo de pesquisadores do Grupo Interinstitucional de Pesquisa em Telejornalismo (GIPTele). E-mail: mmnegrini@yahoo.com.br.

** Jornalista. Doutora em Comunicação pela UFSM. Professora da Universidade Federal do Pampa (Unipampa) - Campus São Borja. Integrante do núcleo de pesquisadores do Grupo Interinstitucional de Pesquisa em Telejornalismo (GIPTele), do grupo Comunicação Televisual (COMTV) e do grupo Jornalismo em Rede e Convergência. E-mail: robertaroosthier@gmail.com.
} 
Datas de submissão e aprovação do artigo

Submissão: 27/6/2019

Aceito: $19 / 8 / 2020$

\section{INTRODUÇÃO}

Os modos do fazer do telejornalismo e o exercício de suas rotinas cotidianas são desafios constantes para os profissionais que trabalham nesta seara. Os telejornais comportam em sua constituição diversos elementos, como imagéticos, sonoros e gráficos, os quais são complementares no decorrer de uma reportagem e são precípuos para a produção de sentidos sobre as informações passadas para os espectadores.

Fazer telejornalismo é uma atividade dotada de complexidades pois, além de se tratar de um trabalho que envolve a organização de muitos códigos, está relacionada ao exercício de um tipo de jornalismo que tem amplo alcance na sociedade. De acordo com reportagem de 2017 do Portal G1, que mostrou dados da "Pesquisa Brasileira de Mídia 2016 - Hábitos de Consumo de Mídia pela População Brasileira", naquele momento, cerca de $90 \%$ dos brasileiros usavam a televisão para se informar sobre os acontecimentos do país, e 63\% tinham a televisão como o seu principal meio de informação. As informações da Pesquisa assinalam que a TV é o principal meio de comunicação do país quando falamos em meios utilizados para obtenção de informações. "Praticamente nove de cada dez entrevistados fizeram menção em primeiro ou segundo lugar à TV como o veículo preferido para obter informações (BRASIL, 2016, p.16). E ainda, de acordo com o Kantar IBOPE ${ }^{1}$, nos últimos cinco anos, o tempo médio de consumo da televisão teve um aumento de 34 minutos. As informações citadas demonstram a importância e o alcance da televisão em nível de Brasil e a significação que ela tem no contexto brasileiro, o que faz com que aumente a importância de falarmos em inclusão e acessibilidade neste veículo.

Analisando o alcance televisivo, Gomes (2018, p.82) assinala: "Com um mercado de aproximadamente $95 \%$ de telespectadores, a televisão no Brasil sagra-se como o meio de comunicação de maior relevância do país". E o autor (2018, p.82) ainda faz ponderações sobre a importância do veículo no cenário brasileiro:

Em um país com dimensões continentais como o Brasil, o meio de comunicação mais importante e que detém papel de destaque no cenário da informação e formação da opinião pública do país ainda é a televisão. Sobretudo, se considerado o atual cenário tecnológico. Dados atualizados do PNAD (2017) afirmam que o aparelho está presente na casa de mais de $95 \%$ dos Brasileiros

A partir do apontamento de Gomes (2018) cabe assinalar que com o desenvolvimento tecnológico, as formas de acesso ao telejornal foram ampliadas. 0 público passou a ter mais possibilidades de contemplação das formas audiovisuais e do jornalismo televisivo através da transmissão via web e do acesso por dispositivos móveis. Desta forma, os desafios das equipes das redações passaram a ser ainda

\footnotetext{
${ }^{1}$ Disponível em: <https://www.kantaribopemedia.com/wp-content/uploads/2020/03/Kantar-IBOPEMedia_Inside-TV_2020-1.pdf> Acesso: 01 de Abril de 2020.
} 
maiores quando o assunto são as rotinas produtivas do jornalismo televisivo. E entre os desafios que se mostram no cotidiano do jornalismo televisivo, diante do quadro de sua ampla inserção entre os públicos, está a perspectiva da produção de conteúdos que possam ser contemplados por pessoas com deficiência.

Em matéria publicada pelo Estadão no dia 21 de junho de 2018, é destacado que o IBGE assinala que, no contexto brasileiro, a proporção das pessoas com deficiência na população é de $6,7 \%$. Os dados do IBGE demonstram a urgência de tratarmos com afinco questões relativas à inclusão no espaço das redações dos veículos de comunicação. As informações do IBGE, que são divulgadas pelo Estadão, implicam na importância de constantes realizações de reflexões sobre inclusão de pessoas com deficiência em todos os níveis na sociedade, inclusive nos meios de comunicação, e adentram na perspectiva de que discussões sobre inclusão e acessibilidade são urgentes para termos sociedades mais justas e igualitárias. Para que possamos falar na efetivação da inclusão, cabe falarmos em acessibilidade. Scoralick (2016, p.3) reflete sobre a acessibilidade:

A acessibilidade é o direito que viabiliza e potencializa os demais direitos e é indispensável para que haja um processo de efetiva inclusão. Ela oferece condições para utilização com segurança e autonomia, total ou assistida, a todos os espaços e meios, pelas pessoas com deficiência ou de mobilidade reduzida.

A autora destaca que o tema acessibilidade nos meios de comunicação começou a ser refletido no ano 2000 e complementa dizendo que, nos dias atuais, a televisão brasileira disponibiliza recursos ${ }^{2}$ como a legenda oculta (closedcaption) e a interpretação na Língua Brasileira de Sinais (Libras) para as pessoas com deficiência auditiva e há o recurso da audiodescrição para os deficientes visuais.

A lei federal $n^{\circ} 10.098$, de dezembro de 2000, regulamentada em 2004 pelo decreto federal 5.296 abordava o tema. Estabeleceu no artigo 17 a eliminação de barreira na comunicação para tornar acessíveis os sistemas de comunicação. E no artigo 18 aborda a implementação de profissionais intérpretes de escrita em braile, linguagem de sinais e guias-intérpretes para facilitar a comunicação direta de pessoas com deficiência sensorial e dificuldade de comunicação (SCORALICK, 2016, p.4).

Mas, apesar da grande importância de recursos de acessibilidade para a sociedade e para a manutenção dos direitos dos cidadãos, sabemos que nem todos os telejornais disponibilizam recursos como a interpretação em libras e a audiodescrição. No caso da audiodescrição, são raros os exemplos que podem ser

\footnotetext{
2 Scoralick (2016, p.3) explica estes recursos: "Segundo a Norma Complementar $n^{\circ}$ 01/2006, do Ministério das Comunicações (MC), que estabelece os recursos de acessibilidade na TV aberta, a legenda oculta é a transcrição, em língua portuguesa, dos diálogos, dos efeitos sonoros, som ambientes e outras informações que que não poderiam ser percebidos ou compreendidos por pessoas com deficiência auditiva. A Janela de libras é um espaço na tela em que as informações são interpretadas na Língua Brasileira de Sinais. A audiodescrição é definida como a narração, em língua portuguesa, integrada ao som original da obra audiovisual, contendo descrições de sons e elementos visuais".
} 
visualizados na seara brasileira. Scoralick (2016, p.5) acrescenta que ocorreram discussões sobre a importância da aplicação da audiodescrição na televisão analógica, mas a obrigatoriedade foi definida só para a televisão digital. "Para ter programação com audiodescrição basicamente o usuário deve apertar a tecla SAP (second áudio program) no controle remoto do televisor e acionar um outro canal de áudio que tenha o recurso de AD".

Devido a sua importância para o contexto social, a inclusão deve ser pensada em relação aos mais diversos meios de comunicação, inclusive nos telejornais universitários. Cabe ponderar que os telejornais universitários têm papel que vai muito além do ensino de telejornalismo, eles adentram na seara de problematização da realidade e de construção da cidadania. Desta forma, as perspectivas inclusivas são precípuas para que seu papel social seja desempenhado. A fim de problematizarmos os telejornais desenvolvidos no contexto das universidades em relação à inclusão, este artigo tem como objetivo fazer uma reflexão sobre as práticas inclusivas desenvolvidas em telejornais universitários, com olhar específico ao Pampa News, desenvolvido na Universidade Federal do Pampa e já bastante consolidado; e ao Em Pauta TV, desenvolvido na Universidade Federal de Pelotas desde o ano de 2016. O método de análise será o observacional ${ }^{3}$ (GIL, 2008).

\section{TELEJORNALISMO UNIVERSITÁRIO E INCLUSÃO}

Os telejornais ocupam, dentro da programação televisiva, um espaço de identificação de conteúdos referenciais, que atraem a atenção e os olhares de diversos públicos. São responsáveis por apresentar acontecimentos significativos do cotidiano, com repercussões que podem ser de nível local, regional, nacional e até mundial. Vizeu (2009, p.77) assinala a importância do telejornalismo e destaca o seu papel de mediação entre os fatos e o público:

O jornalismo, em particular o televisivo, é uma forma de conhecimento crítico que tem como preocupação interpretar a realidade social (Gomis, 1991), (Genro, 1987), (Meditsch, 1992), (Tuchmann, 1983). É resultado de uma atividade profissional de mediação vinculada a uma organização que se dedica basicamente a interpretar a realidade social e mediar os que fazem parte do "espetáculo mundano" e o público. Compartilhamos com a afirmação de Gomis (1991) e consideramos que a mídia não só transmite, mas prepara e apresenta uma realidade dentro das normas e das regras do campo jornalístico contribui

\footnotetext{
${ }^{3}$ Para Gil $(2008$, p.16), o método observacional é: “[...] um dos mais utilizados nas ciências sociais e apresenta alguns aspectos curiosos. Por outro lado, pode ser considerado como o mais primitivo, e consequentemente o mais impreciso. Mas, por outro lado, pode ser tido como um dos mais modernos, visto ser o que possibilita o mais elevado grau de precisão nas ciências sociais. Tanto é que em Psicologia os procedimentos de observação são frequentemente estudados como próximos aos procedimentos experimentais. Nestes casos, o método observacional difere do experimental em apenas um aspecto: nos experimentos o cientista toma providências para que alguma coisa ocorra, a fim de observar o que se segue, ao passo que no estudo por observação apenas observa algo que acontece ou já aconteceu".
} 
Vizeu e Correia (2007) apontam o telejornalismo como um lugar de referência. Nessa perspectiva, é importante considerar o processo de produção jornalística audiovisual responsável e ética, atentando, sobretudo, para a questão do ensino de telejornalismo nas instituições de ensino superior.

É função das universidades promover a formação de cidadãos livres e com potencial reflexivo, através do desenvolvimento de suas capacidades críticas. Concordamos com Ramos Júnior (2009) quando diz que a universidade é um local que deve ser reconhecido por proporcionar desenvolvimento humano, regional e sustentável na seara das sociedades contemporâneas, tendo como foco importante a geração de conhecimento aos alunos e a aplicação de tais conhecimentos na realidade social. Ela deve atentar para que a sociedade tenha uma conjuntura que preze por mais justiça e por igualdade, “[...] considerando a necessidade de ser acessível a toda a sociedade, em todos os níveis sociais para que haja inclusão social, exercendo tanto uma função social quanto política" (RAMOS JUNIOR, 2009, s/p). Nesse sentido, a produção de telejornais universitários está além dos resultados obtidos com a prática, eles estão voltados à formação de cidadãos engajados com o contexto social.

Este espaço de aprendizagem deve ser compreendido, também, pelo acesso à informação acessível e pelo exercício da cidadania, mesmo que as iniciativas de programas que utilizam recursos com acessibilidade ainda sejam bastante raras. A inserção de recursos de acessibilidade deve começar pelos espaços de formação de cidadãos, como as universidades. É imprescindível que um local de formação de futuros jornalistas esteja atento para questões de inclusão de pessoas com deficiência.

\begin{abstract}
Trata-se da questão da acessibilidade enquanto caminho necessário de inclusão de um certo tipo de público hoje excluído de maneira geral, das possibilidades de consumo dos telejornais. Ou seja, apresenta-se aqui o necessário olhar para a diversidade da audiência e de seu direito constitucional à informação - especialmente nos moldes da TV aberta - de um lado, enquanto de outro a necessidade de considerar também a Lei da Acessibilidade na formação dos futuros telejornalistas (PICCININ, NEGRINI e ROOS, 2017, p.6).
\end{abstract}

O telejornalismo universitário pensado, tanto para os públicos, quanto para suas diversidades e inclusões, tem papel fundamental no processo de ensinoaprendizagem. Nessa perspectiva, a evidência apresentada em termos dos telejornais universitários diz respeito à potencialização da formação dos futuros jornalistas, na medida em que oportuniza o diálogo entre teoria e prática. Brasil e Emerim (2011) ressaltam que "[...] a formação do jornalista televisivo deve ser levada a sério, vista a importância que estes profissionais tendem a assumir na vida social quando se inserem no mercado de trabalho" (2011, p. 4). Negrini e Roos (2017, p.69) refletem sobre a importância dos telejornais universitários para a formação dos estudantes da área do jornalismo:

Os telejornais universitários são fundamentais no contexto do ensino de telejornalismo. Eles são ambientes privilegiados de aprendizado acerca das práticas do jornalismo de televisão e de vivência das rotinas cotidianas de uma redação de TV. A formação de um jornalista de TV precisa ir muito além dos espaços teóricos de sala de aula. Faz- 
se fundamental a conformação entre as rotinas teóricas e as práticas, que têm naturezas complementares.

Falando da importância dos telejornais universitários como suporte ao aprendizado, concordamos com Carravetta (2009) quando diz que a formação de um profissional de televisão se dá pela interação entre teoria e prática. A teoria dá bases conceituais sobre os modos de fazer TV e sobre questões que perpassam o telejornalismo em si; e a prática dá bases para que se efetivem o conhecimento técnico e o conhecimento sobre a vida em uma redação.

Diante do advento da web, diversas características se somam, facilitando o desenvolvimento de tevês universitárias e potencializando a difusão de informações. A distribuição de conteúdos sem custos, a liberdade editorial e a alta visibilidade privilegiam a ambiência digital, dessa forma, as produções audiovisuais praticadas nos cursos de Jornalismo podem ser transmitidas através de sites, páginas nas mídias sociais, canais como o YouTube, ou ainda, por aplicativos para dispositivos móveis (PICCININ, NEGRINI e ROOS, 2017).

O meio digital, através de canais de conteúdos, facilita o uso de recursos com acessibilidade, permitindo a combinação de mecanismos de informação e recursos interativos. Um exemplo são os aplicativos que podem ser baixados nos smartphones, que atendem as necessidades individuais, possibilitando, assim, um número maior de usuários beneficiados. Para além disso, a experiência da rotina televisiva associada ao desenvolvimento das habilidades na produção de recursos acessíveis permite o estímulo à reflexão crítica, responsável e sensível dos estudantes, que precisam estar atentos sobre a forma em que o texto e a imagem estarão chegando a todas as pessoas. Sobre isso, Sousa destaca:

[...] os equivalentes não textuais de texto (por ex., ícones, discurso pré-gravado ou um vídeo de uma pessoa a traduzir o texto para língua gestual podem tornar os documentos acessíveis a pessoas que tenham dificuldade em aceder a texto escrito, entre elas as que tenham deficiências cognitivas, dificuldades de aprendizagem ou surdez. Os equivalentes não textuais de texto podem também ser úteis a pessoas que não lêem. Exemplo de um equivalente não textual de informações visuais é a descrição sonora. A descrição falada de uma passagem visual de uma apresentação multimédia beneficia quem não consegue ver as informações visuais. (SOUSA, 2009, p.282)

O desafio dos telejornais universitários com veiculação na internet, portanto, está em aproveitar as especificidades da web, evitando a simples transposição dos conteúdos que seriam de TV no espaço virtual, além do desenvolvimento de produtos acessíveis. A veiculação dos programas reflete a visão de que a Universidade "deve ser o espaço da experimentação de novos formatos de conteúdos, incluindo a construção de aplicações interativas para a TV Digital e para a convergência de mídias" (PASCHOAL NETO, 2009, p.44). Este é o caso do projeto Pampa News, da Universidade Federal do Pampa - Unipampa - campus São Borja, e do Em Pauta TV, telejornal quinzenal produzido por alunos do curso de Jornalismo da Universidade Federal de Pelotas, os quais vamos observar e apresentar reflexões a partir de agora. 


\section{PERSPECTIVAS INCLUSIVAS NO PAMPA NEWS}

Vamos discorrer sobre o Pampa News e as perspectivas de inclusão nele apresentadas. Vamos apresentar as abordagens em caráter observacional (GIL, 2008). O Pampa News é um projeto de extensão vinculado ao curso de Jornalismo e Publicidade e Propaganda da Unipampa, mas que surgiu, inicialmente, como atividade prática da disciplina de Laboratório de Telejornalismo I (2012/1), com a proposta de apresentar conteúdos próximos e relevantes para as comunidades universitária e local. Logo depois, se tornou tema de um Trabalho de Conclusão de Curso, que lançou a experimentação para o programa ser exibido semanalmente. 0 projeto experimental foi levado a diante e se tornou um projeto de extensão, promovendo um espaço de experiência prática de jornalismo audiovisual para os alunos de Comunicação Social.

Levando em consideração a trajetória dos vários programas produzidos desde sua criação, percebeu-se que o nome Pampa News já era reconhecido pela comunidade do Campus São Borja. As coberturas especiais desenvolvidas nas disciplinas fortaleceram a marca com o público interno da Universidade. Então, em 2013, consolidou-se o Pampa News na UNIPAMPA, através de uma inserção real na comunidade são-borjense. O programa noticioso semanal coloca em prática, de maneira eficaz e contínua, o papel social da Universidade e do Jornalismo.

A produção do telejornal educativo semanal na web apresenta questões sociais relacionadas aos contextos em que a UNIPAMPA está inserida. É uma atividade que prevê o contato direto com a comunidade local através da coleta e execução de pautas para reportagens audiovisuais, apresentadas semanalmente no canal: youtube.com/pampanewsunipampa e distribuídas na página: facebook.com/ pampanewsunipampa.

Com um ano de produção, o programa tornou-se referência de mídia local. A equipe passou a ser solicitada para a cobertura de eventos e acontecimentos importantes, além do crescente número de visualizações. Com isso, foi necessário tornar o programa acessível pelos recursos da web.

Nesse sentido, o programa recebeu a tradução na Linguagem Brasileira de Sinais nas edições, o que contou com a colaboração e orientações de uma professora de Libras da Unipampa. A professora intérprete é surda e, diante dessa situação, a equipe precisou adequar-se a uma série de injunções novas. Todas as reportagens devem ser decupadas na lauda e entregues com, pelo menos, um turno de antecedência para que ela possa fazer a leitura. Além disso, depois de gravado o off $^{4}$, é preciso cronometrar cada parágrafo narrado e passar o tempo para que ela desenvolva a interpretação em sincronia com o que está sendo falado. Essa situação não permite que pautas factuais recebam a interpretação em libras, pois o programa é gravado uma vez na semana.

\footnotetext{
$4 \mathrm{O}$ off é o texto da matéria que é gravado pelo repórter ou apresentador e que depois é coberto com imagens ou dados sobre o acontecimento (BARBEIRO; LIMA, 2002).
} 
Imagem 1: Apresentação: Fahen Carvalho com a intérprete de Libras Keli Kraus.

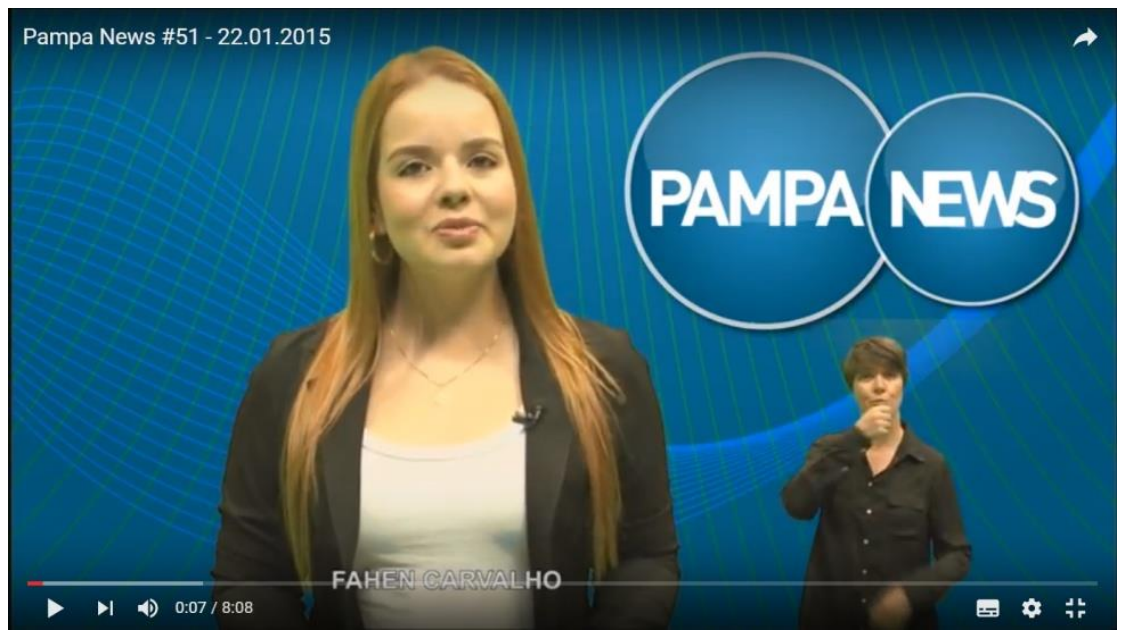

Fonte: https://www.youtube.com/watch?v=yf9zVSnYsOk

O fundo da janela de libras também foi retirado, aumentando-se, assim, o tamanho do espaço ocupado pela intérprete, o que melhora a visualização da linguagem. Esses detalhes importantes para fazer realmente uma produção acessível foram obtidos através das observações realizadas pela professora intérprete.

\section{PERSPECTIVAS INCLUSIVAS NO EM PAUTA TV}

O Em Pauta TV é um telejornal quinzenal produzido por alunos do curso de Jornalismo da Universidade Federal de Pelotas. O programa está registrado na instituição como sendo de extensão universitária - desta forma, visa levar a UFPel até a comunidade pelotense por meio de divulgação de notícias, reportagens e entrevistas televisivas. Vamos discorrer sobre o programa e apontar alguns aspectos relativos à inclusão, também em nível observacional (GIL, 2008).

O projeto Em Pauta TV está em funcionamento há pouco mais de quatro anos e, como a UFPEL não possui um canal de televisão, tem sua efetivação através de uma parceria com a TV Câmara de Pelotas, que exibe o programa quinzenalmente. Também é transmitido nas redes sociais. Conta com o apoio de quatro técnicos em audiovisual, de duas professoras do curso de jornalismo e de uma aluna bolsista, além de voluntários que dão suporte ao desenvolvimento do telejornal.

As produções do programa são voltadas para a comunidade acadêmica e para a sociedade pelotense de forma geral. As pautas são recheadas de assuntos locais e relacionadas a atividades ligadas à universidade e à educação, que são de interesse do público da instituição e da cidade de Pelotas. Da mesma forma, o quadro entrevista, que tem cerca de cinco minutos de duração em todas as edições, é voltado a levar ao público uma reflexão sobre um tema importante da universidade ou da cidade de Pelotas que esteja em discussão no momento.

A produção do programa está relacionada, também, com o ensino de telejornalismo. As coordenadoras, durante o processo produtivo de cada edição, dão constante suporte aos alunos, fazendo apontamentos com foco no aprimoramento dos conhecimentos e na construção do conhecimento. $E$ os técnicos estão 
constantemente voltados a dar suporte no processo de captação de imagens e na edição de reportagens.

Cabe apontar também que produções feitas nas disciplinas de Telejornalismo e de Telejornalismo II, do curso de Jornalismo da UFPEL, também são trabalhadas com objetivo de transmissão no programa. Com foco em ir ao ar no telejornal, os alunos das duas disciplinas precisam buscar constantemente o aprimoramento da produção telejornalística, de texto e de questões técnicas.

Com foco no desenvolvimento dos conhecimentos dos alunos participantes, as coordenadoras organizam oficinas com profissionais das televisões locais junto aos alunos. As oficinas são focadas no compartilhamento das experiências dos profissionais e na aproximação dos discentes junto aos meios de comunicação de Pelotas. Entre as oficinas que ocorrem, cabe destacar: oficinas de produção de texto de telejornalismo; oficina de captação de imagens; e oficina de edição.

Vale destacar que como o programa também é transmitido na internet, um foco da equipe é sempre buscar a proximidade com o público através de uma linguagem simples e de fácil entendimento. O programa conta com um quadro voltado para a divulgação de projetos de pesquisa e de extensão da UFPEL. Desta forma, todas as edições apresentam assuntos que contemplem estas searas. Um grande desafio aos alunos e às professoras é transmitir o conteúdo de pesquisa em linguagem acessível ao público e fazer com que a pesquisa seja um assunto que gere interesses na comunidade em geral.

Com a efetivação do programa como um espaço de divulgação de ações da Universidade para a comunidade pelotense, percebemos que ele se tornou referência dentro da UFPEL e entre os membros da comunidade universitária. Professores e alunos passaram a nos procurar dando sugestões de pautas e demarcando assuntos relevantes para possíveis reportagens. Em razão disso, verificamos a importância de tornar o Em Pauta acessível aos mais diversos públicos. E, no decorrer do ano de 2018, começamos a verificar a indispensabilidade de estarmos atentos ao acesso das pessoas com deficiência aos conteúdos. Estamos inseridos no Centro de Letras e Comunicação da UFPEL e temos vários professores que são surdos no curso de Letras e que estavam sem acessibilidade ao Em Pauta. Em um primeiro momento, pensamos na importância de colocar uma janela com tradução para Libras. Ao amadurecermos a ideia, verificamos que não teríamos estrutura para fazermos este processo. Diante da impossibilidade da tradução para Libras, verificamos que o uso de legendas poderia ser uma saída inicial - claro que queremos aprimorar para a inserção da janela de Libras no futuro. As legendas são colocadas na escalada e nas cabeças feitas pelos apresentadores, em todas as falas presentes em reportagens e, também, na entrevista, que ocorre no final da edição.

Nas rotinas de produção do Em Pauta, o processo de legendar é feito pelo discente responsável pela reportagem, com a ajuda do bolsista e dos técnicos em audiovisual envolvidos no projeto. As professoras fazem a correção textual ainda na lauda e depois voltam a fazer a correção no vídeo, antes do fechamento da matéria. Sobre isso, vale destacar as palavras de Monteiro que versam sobre os cuidados com a utilização das fontes nas legendas:

Como medida preventiva, o ideal é a utilização de textos com fontes grandes. Estudos em usabilidade demonstraram que fontes com menos de 18 pontos de dimensão são de difícil leitura na televisão [Krebs et al, 2000]. Esta 
estimativa, entretanto, varia conforme o middleware utilizado, pois cada um possui seu tipo específico de fonte, sendo que os tamanhos variam entre eles. Mesmo assim, esta é uma boa medida inicial. (MONTEIRO, 2002, p.50)

No caso do conteúdo das reportagens, o texto já se encontra na lauda de cada matéria e, no caso das cabeças e escalada, o texto está no espelho do telejornal. $E$, em relação à entrevista, é feita a decupagem pelo bolsista para que seja legendada.

Imagem 2: Apresentadores, Elenice Fouch e Jefferson Perleberg, em uma cabeça de reportagem, que é legendada

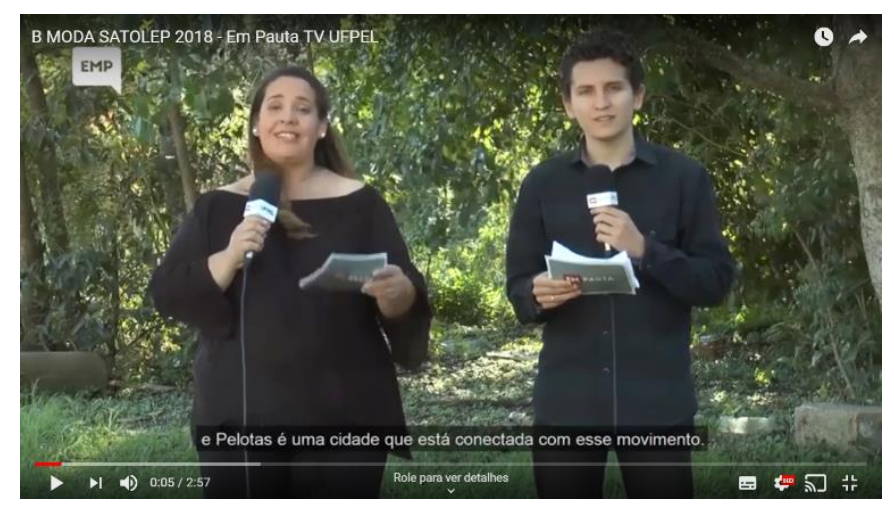

Fonte: https://www.youtube.com/watch?v=JWtAR5H6yVE

Imagem 3: Repórter LeniseSlawski em uma matéria com legenda

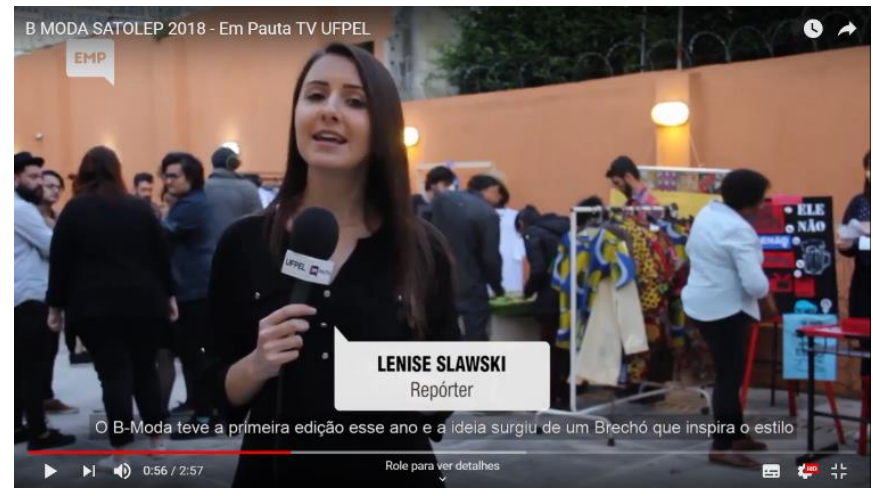

Fonte: https: / /www.youtube.com/watch?v=Jl591BirrCk

Com a inserção das legendas no programa, o público da UFPEL passou a ter mais satisfação com o conteúdo ${ }^{5}$, por estarmos cuidando de um programa telejornalístico vinculado à instituição pensando na acessibilidade. Mas, sabemos que os desafios ainda são muitos e que devemos pensar no aprimoramento constante de iniciativas de inclusão.

5 Foi possível visualizar o aumento da satisfação do público do Em Pauta através de manifestações nas redes sociais do programa e, também, por comentários feitos diretamente aos membros da equipe. 


\section{CONSIDERAÇÕES FINAIS}

Como já abordamos, os modos de fazer telejornalismo e a produção telejornalística são permeados por complexidades e exigem o domínio de vários códigos por parte dos repórteres. E, com o desenvolvimento tecnológico, que proporcionou a ampliação das bases de acesso aos produtos jornalísticos audiovisuais, os desafios dos telejornalistas ficaram ainda maiores, tendo que levar em conta as especificidades das diversas telas de contemplação dos produtos televisivos.

Ainda dentro da discussão dos desafios da produção telejornalística, um tema que aponta é a produção de produtos acessíveis aos mais diversos públicos, inclusive às pessoas com deficiência. A audiodescrição surge como uma alternativa para que os cegos possam ser incluídos e a janela de Libras surge como um suporte aos surdos. Claro que sabemos que, no cenário brasileiro, ainda estamos longe do ideal em nível de inclusão.

Ao falarmos de acessibilidade e de inclusão, vem à tona o pensamento de que os telejornais universitários precisam contemplar estas iniciativas, pois as universidades são espaços que precisam prezar pela construção da cidadania e pela igualdade social. Neste trabalho, nos focamos na reflexão sobre as práticas de inclusão do PampaNews, da Universidade Federal do Pampa, e do Em Pauta TV, da Universidade Federal de Pelotas.

Em relação ao Pampa News, como um telejornal universitário mais consolidado, o uso da tradução para Libras se mostra como uma atividade desafiadora para a equipe de produção, mas como um recurso profícuo para incluir o público surdo. Fazer o trabalho não é simples, abarca uma demanda de organização bastante ampla, mas o resultado tem sido satisfatório perante a comunidade.

Já em relação ao Em Pauta TV, como um espaço de produção universitária bem mais recente, apenas as legendas estão sendo usadas, mas, mesmo assim, elas têm tido interessante aceitação diante do público da Universidade Federal de Pelotas. A equipe de produção, com o tempo, quer introduzir a tradução para Libras.

A inclusão se mostra como um desafio na prática dos telejornais universitários, mas, em um espaço em que é voltado à reflexão e à formação de uma massa crítica, deixar esta perspectiva de fora iria contra toda a essência institucional.

\section{REFERÊNCIAS}

BARBEIRO, Heródoto; LIMA, Paulo Rodolfo de. Manual de Telejornalismo: os segreos da notícia na TV. Rio de Janeiro: Campus, 2002.

BRASIL, Antônio; EMERIM, Cárlida. Por um modelo de análise para os telejornais universitários. In: Seminário Internacional Análise de Telejornalismo: desafios teóricometodológicos, 2011, Salvador. Disponível em:

analisedetelejornalismo.wordpress.com. Acesso em:25 de junho de 2016.

BRASIL. Presidência da República. Secretaria Especial de Comunicação Social.

Pesquisa brasileira de mídia 2016: hábitos de consumo de mídia pela população brasileira. Brasília: Secom, 2016. 
CARRAVETTA, Luiza Maria Cezar. Construindo o telejornal. Porto Alegre: Armazém Digital, 2009.

ESTADÃO. Com nova margem de corte, IBGE constata $6,7 \%$ de pessoas com deficiência no Brasil. Disponível em: https: //educacao.estadao.com.br. Acesso em: 22 de maio de 2019.

G1. TV é o meio preferido de $63 \%$ dos brasileiros para se informar, e internet de 26\%, diz pesquisa. Disponível em: https://g1.globo.com. Acesso em 22 de maio de 2019.

GIL, Antonio Carlos. Métodos e técnicas de pesquisa social. São Paulo: Atlas, 2008.

GOMES, R. J. Televisão e Telejornalismo: Desafios à Produção e Edição em Tempos de Convergência. Revista Comunicação Cultura e Sociedade, v. 1, p. 82-95, 2018.

KANTAR IBOPE MEDIA. Inside TV: experiências, influências e as novas dimensões do vídeo. Disponível em: <https://www.kantaribopemedia.com> Acesso: 01 de abril de 2020.

MONTEIRO, Marcelo Souto. TV Interativa e seus Caminhos. Tese de mestrado da Universidade Estadual de Campinas. (2002, p. 2-3).

NEGRINI, Michele; ROOS, Roberta. Tecnologias comunicacionais e telejornalismo universitário: um caminho de transformações. Revista Alterjor, v. 16, p. 67-80, 2017.

SCOLA, Alvaro. Os cinco melhores aplicativos do Android para pessoas com deficiência visual. Disponível em: https://olhardigital.com.br. Acesso em 21 de junho de 2019.

RAMOS JUNIOR. Hélio Santiago. A função da universidade na sociedade do conhecimento. Disponível em: http://www.egov.ufsc.br. Acesso em: 21 de junho de 2019.

PASCHOAL NETO, José Dias. As TVs universitárias como espaços de experimentação da interatividade na TV digital. In: NUNES, Pedro. Núcleo de Pesquisas em Mídias, Processos Digitais e Interatividade - NUMID - 2009.

PICCININ, Fabiana; NEGRINI, Michele; ROOS, Roberta. Telejornalismo universitário e acessibilidade: um caminho em formação. RUMORES(USP), v. 12, p. 313-332, 2018.

SCORALICK, Kelly. Telejornalismo e acessibilidade comunicacional: um olhar para o outro com deficiência. Anais $14^{\circ}$ Encontro Nacional de Pesquisadores em Jornalismo, Palhoça, SC, 2016. Disponível em: http://sbpjor.org.br. Acesso em: 14 de outubro de 2018. 
SOUSA, Joana Belarmino de. Mídias digitais: acessibilidade na web e os desafios para a inclusão informacional. In: NUNES, Pedro. Núcleo de Pesquisas em Mídias, Processos Digitais e Interatividade - NUMID - 2009.

VIZEU, Alfredo. O telejornalismo como lugar de referência e a função pedagógica. Revista FAMECOS, v. 01, p. 77-83, 2009.

VIZEU, Alfredo, CORREIA, João Carlos. A construção do real no telejornalismo: do lugar de segurança ao lugar de referência. In: VIZEU, Alfredo. A sociedade do telejornalismo. Petrópolis: Vozes, 2007. No prelo. 
